\title{
Research on German Teaching Method Innovation in Internet Environment
}

\author{
Jinglan Liu \\ School of Foreign Languages, Wuhan Polytechnic University, Wuhan, 430028, China
}

Keywords: Internet; German teaching; teaching method; innovation research

\begin{abstract}
With the progress of information technology revolution, Internet has gained rapid development and gradual popularity. The ability to mastering and using network techniques has become increasingly important in people's daily work and life and it has turned out to be a necessity in job hunting. Under this trend, the use of students' familiarity with the Internet and the rich resources on the Internet for foreign language learning provide more opportunities for foreign language teaching and broader development prospects. From a variety of perspectives, this article expounds the advantages of the Internet in terms of resources; it also studies in detail the importance of using the Internet for German teaching in terms of enhancing students' comprehensive ability and improving teachers' teaching effectiveness.
\end{abstract}

\section{Introduction}

The advancement of information technology has promoted the rapid development and wide application of the Internet. The construction of university networks has provided technical support and foundation for the Internet-assisted foreign language teaching. Today's society needs highly qualified German language talents. The traditional German language teaching is that students passively and mechanically accept German knowledge under the teacher's "cramming style". Without a real German context and cultural feelings, it is hard for the students to be really capable of using German.

The application of the Internet in German teaching provides rich resources for teaching, as well as an online platform for communication. It has broken the limitation of time and space that hinders the development of traditional teaching. The establishment of a three-dimensional graphic, video, and phonological learning environment to improve students' interest in learning, language skills, and German cultural literacy will help cultivate applied, high-quality German talents.

\section{The Long-standing Disadvantages in Traditional German Teaching}

The traditional German teaching is centered on teachers, classrooms, and textbooks. The teachers conduct simple teaching according to the focus of the book knowledge and the focus of the exam, neglecting the cultivation of the students' language ability and their practical application. The teaching is time-consuming, inefficient, and high-grade and low-ability. The traditional teaching phenomenon cannot train qualified German application talents for the society. Its main drawbacks are as follows:

Classroom Teaching is Teacher-centered and Lacks Teaching Interaction between Teachers and Students. The main problem in Chinese German classroom teaching, in the words of some German teachers, is that the way of Chinese German classroom teaching is like a one-way street. The most serious problem in this type of classroom teaching is the lack of time for students to speak, with teacher at the core. Moreover, Chinese teachers are usually textbook-centered, so that textbooks have an authoritative status in Chinese classrooms. For students, the teacher is only a carrier of book knowledge. Teachers usually spend more than half of class time in explaining new vocabulary and grammatical phenomena. The arrangement of German teaching in the classroom is basically in the control of teachers. There is almost no possibility for students to take part in the arrangement of a complete class or a part of it together with their teachers. This traditional German pedagogy usually only pays attention to a formal linguistic knowledge, whereas the communicative competence of the language is often overlooked. As a result, the ability of many students to listen and speak in German cannot be improved. And this type of classroom teaching directly leads to the lack of creativity and independence of students. 
The Compilation of German Textbooks is Incompatible with the Current Teaching Methods. The compilation of German textbooks sometimes cannot keep up with the needs of the situation. At present, the materials for German teaching in China's higher learning institutions are written more than ten years ago, which lack the adaptability to the changing situation and the practicability as well. However, foreign language textbooks are time-sensitive, and they need to be constantly updated to keep up with the times. On the other hand, some textbooks neglect the cultivation of language communication skills and application skills. In addition, many German textbooks are designed for the cultivation of general-purpose talents, which is subject to the limitations of classroom teaching time. Such a teaching aim is unable to fulfill the need of people who need further training in professional German knowledge as they are engaged in different career orientations in the future. And German textbooks in this area are very scarce.

The Conflict between the Adoption of a New Teaching Method and German Teaching in Colleges and Universities. In recent years, German teaching in China is gradually changing, and many schools are also trying to reform German teaching. Some teachers have gradually begun to use communicative teaching methods in their teaching, and the "Audio-lingual Method" and the "Audio-visual Method" are gradually being adopted in German teaching. Although more and more new teaching methods are being adopted in most schools, there are also some new problems. To be more specifically, they are designed only to achieve an active classroom atmosphere. For example, in recent years, many colleges and universities have been promoting "inquiry-based teaching methods" and "self-directed learning." This should be a kind of quality education. It requires teachers to guide students to find problems and solve problems on their own, so as to develop students' autonomous learning. However, if such methods are adopted only for the purpose of achieving an active classroom atmosphere and are conducted to explore things only for the purpose of exploration, it is another new misunderstanding. Some teachers were garrulous in class and the classroom atmosphere seemed to be very active, but it did not help German teaching, as students did not really learn anything. Nowadays, German-majors in Chinese universities and colleges are mostly zero-based students when they enter university, and it takes a lot of time and energy to acquire a brand new foreign language in four years. Therefore, the time for class teaching is especially precious in this sense. If we adopt new teaching methods just to activate the classroom atmosphere, this will take up a lot of classroom teaching time and it will inevitably affect the actual effect of teaching. Especially, for these zero-based students, if teachers do not explain the grammar and vocabulary of the text at all, students will find it difficult to have a good understanding of the complex grammatical phenomena that appear in the text.

\section{Internet is Applied to German Teaching Research}

Online Searching and Online Roaming. The search engine provides a powerful search function that can provide a large number of German language learning web pages and teaching materials that can offer extended information and help to German teachers in their teaching, inspiring students' enthusiasm for learning. Teachers can design teaching topics according to the syllabus, and give students sufficient online search preparation time to complete the organization, design and report of the special report. Teachers need to provide students with healthy and effective search engines according to the topic content. For example, the Hotbot search engine, which is the world's largest search engine for storage, is a good choice. It can limit the range of language and subject to facilitate search, and can instantly translate the search content into other languages, which are crucial to German-learning. Lycos's search language is of as many as $37 \mathrm{kinds}$, and its assistant topic is very detailed, the operation is also easy to understand, and its feature is that it can provide a search path for audio and video files and pictures. The search information provided by the search engine can help students build the framework of knowledge based on the teacher's teaching topics and it can also improve students' online browsing skills. Each German-speaking country has its own web page on the Internet. It introduces the local landscapes, folk customs, cultural products and entertainment items and other humanistic geography situations to visitors, through which students can understand the German language environment and deepen their understanding of German culture. Teachers can set up a teaching situation of a travel plan to help 
students train their reading comprehension skills, expand their vocabulary, deepen their understanding of grammar, and enable them to apply their knowledge to practice in the process of data collection.

Online Reading. The high-speed information transmission of the Internet ensures the promptness and comprehensiveness of information materials, and the Internet has a large reserve of news and information. Teachers can provide students with online reading through multimedia teaching. For example, teachers can search Germany's authoritative newspapers and news pages for some incidents in the multimedia classroom, and show the search process and the search content to students, and then require students to read aloud and to conduct an oral explanation. Meanwhile, teachers can also search related articles and reports according to the incidents, and then compare the article structure and their difference in expression so as to find out the rules of grammar, which is helpful in improving the accuracy and fullness of students' oral expression. In this way, students can learn German in real context and the integration between them and German language will be strengthened.

Online Dialogue Platform. Online chat in German language assisted by computer keyboard can train students' comprehensive ability. Students have to organize language and express opinions in a real communication environment, realizing the integration of German vocabulary, sentence patterns, grammar and cultural knowledge. The immediacy of online chat requires students' reading ability, comprehension ability, and quick response ability. Therefore, online chat needs to be based on solid language knowledge and can be used as an important way to learn German. Teachers can use interpersonal resources to contact German-speaking colleagues, friends, and students to set up chat rooms or provide a website of healthy chat rooms to guide students to engage in purposeful online chats, such as http: / / chat. Schulweb. De, the members of which are mainly students of the basic stage in German learning. They have common topics, basic background knowledge, experience and topics, and are easy to communicate with each other and exchange ideas.

Due to the limitations of the classroom teaching, teachers cannot implement one-to-one counseling to have a keen understanding of students. The application of tools like QQ chat software and WeChat is an extension of traditional teaching methods. Teachers and students all can communicate with each other for better teaching and learning through the chat groups functioned by those software, and this will encourage students to communicate in German and enhance interactive learning.

Taking Internet as a Learning Tool. The Internet has realized the effective integration of global data information, including rich texts, images, audio, video, games, and software data. It is capable of performing full sensory stimuli on students' German language learning and increasing their interest in learning. German teachers should make reasonable use of sharing materials to improve the German teaching environment.

Establishing a German Language Learning Website for Academic Exchanges. As the network develops to today, its form becomes more and more diverse. Having an exclusive space on the Internet is no longer a dream. Everyone can create their own personal web page, such as Dark horse personal free web page, and personal blog provided by large websites such as Sina, Sohu, and MSN. Teachers can create their own personal web pages and put the handouts, notes or supplemental materials on the web pages for students to download. At the same time, message boards can be opened to answer questions from students. This will not only help students to establish good study habits but also develop their self-learning skills. As a teacher, in addition to helping students use the Internet to learn, they can also use their own web pages as a platform to communicate with other teachers. In the aspect of scientific research especially, they are supposed to communicate and cooperate with each other to further promote their self-building on the one hand, and contribute more to the research and development of German teaching and the language itself on the other.

\section{Issues that Need Attention in the Application of Internet in German Teaching}

The Design of the Courseware should be Reasonable. As German language teachers are not computer majors, the making of courseware is limited by their inadequate computer operation ability. Therefore, teachers should receive professional training to improve their skills in controlling multimedia 
and computer techniques so that they can work out excellent courseware that is in consistent with the rule of teaching and the cognizant law.

To Guide a Healthy Internet Usage. The Internet plays an important role in German teaching, but we should not exaggerate the function of the Internet. We should maintain the rationality in using the Internet and dialectically combine traditional teaching with Internet-assisted teaching. Being complex and diversified, the integrated resources on the Internet consist of many harmful information that would have an adverse impact on students both physically and mentally. When guiding them to use the Internet, teachers must attach great importance to the cultivation of students' values and help them consciously reject bad information, thus creating a favorable Internet application learning environment.

\section{Summary}

Under the background of "Internet Plus", the effective combination between information technology and teaching has exploited a new development vision for the traditional teaching mode. The German translation teaching combined with the hybrid teaching mode can overcome the limitations of the traditional teaching mode, effectively solving the problems of less translation time, low class efficiency, low student participation, lack of students' ability training, etc., and it can also break through the boundaries between class time and off-class time, thus improving students' subjective initiative in learning. The translation curriculum mode based on hybrid learning mode not only explores an innovative classroom mode aimed at capacity cultivation in the new era, but also is conducive to the building of a learning society where "everyone learns and they learn everywhere from time to time".

Therefore, the application of Internet-assisted instruction in German teaching is a need for social development. It is a scientific teaching method to improve the learning efficiency and practicality. Professional and considerate German teachers are needed to actively explore and practice an appropriate combination way according to the actual situation. By doing this, we can improve teaching effect, maximize the effectiveness of the Internet in German teaching and we can deliver practical German language talents of high quality to the society.

\section{References}

[1] Xue Zhenhong. Internet-assisted Teaching and the Cultivation of Students' Creative Abilities [J]. Journal of Jilin Normal University (Philosophy and Social Sciences Edition) 2003, (3).

[2] Li Shaoru. Internet and Foreign Language Teaching [J]. Journal of Hubei Normal University (Philosophy and Social Science Edition) 2001,(2).

[3] Liu Xinyi. Network Technology and Foreign Language Education [J]. Journal of Jinan University (Philosophy and Social Science Edition) 2002,(4).

[4] Cai Daiyan. New Exploration of German Teaching Mode [J]. Journal of Changchun Teachers College (Humanities and Social Sciences Edition), 2007(5).

[5] Sun Haiyi. Using Dialogue Teaching to Promote the Cultivation of Students' Creative Ability: A Case Study of British and American Literature Teaching [J]. Education Exploration, 2012(5).

[6] Zhang Fengxian. On the Cultivation of Cross-cultural Awareness in the Teaching of British and American Literature [J]. The New Curriculum, 2015 (10). 